DOI:

УДК 519.6:519.642:550.831.017

П.С. Смолянський, к.т.н., доцент, sirius.ps@gmail.com

А.В. Козіков, старший викладач, kozikov.av@gmail.com

О.В. Шамрай, к.т.н., доцент, elenashamdv@gmail.com

Криворізький національний університет, м. Кривий Ріг

\title{
МАТЕМАТИЧНЕ МОДЕЛЮВАННЯ ПОШУКУ ЕВОЛЮЦЮНУЮЧИХ ЛОКАЛЬНИХ ПОРОЖНИН
}

В статті розглянуті проблеми створення адекватної математичної моделі пошуку еволюиіонуючої порожнини в заданій області на основі загального рівняння гравіметрії. Авторами запропонований метод спрощення тривимірних інтегральних рівнянь гравіметрії та зручні алгоритми для вирімення задачі.

Ключові слова: локалізація порожнин; зворотна задача; інтегральні рівняння; апроксимація; чисельне моделювання.

The article considers the problems of creating an adequate mathematical model for finding the evolutionary cavity in a given region on the basis of the general equation of gravimetry. The authors propose a method for simplifying three-dimensional integral equations of gravimetry and convenient algorithms for solving the problem.

Keywords: void localization; inverse problem; integral equations; approximation; numerical simulation.

\section{Постановка проблеми}

Пошук підземних порожнин стає все більш важливою проблемою в сучасних умовах. Іноді порожнини утворюються за рахунок природніх геологічних процесів, але часто їхнє утворення має техногенний характер. Основну небезпеку при цьому становлять еволюціонуючі порожнини, тобто порожнини, які змінюють своє положення в просторі 3 плином часу. Найчастіше задача локалізації порожнин виникає при видобутку корисних копалин відкритим способом, в бортах, тобто бічних стінках, кар'єрів. Постійні технологічні вибухи провокують утворення та міграцію таких порожнин, а усунення наслідків обвалів, що виникають, вимагає значних витрат коштів та, головне, запобігти можливим людським жертвам. Наприклад, в [1] описані численні випадки катастрофічного виходу на поверхню такого роду порожнин в умовах Центрального гірничо-збагачувального комбінату міста Кривий Ріг. Особливості умов видобутку в кар'єрах роблять актуальною задачу побудови ефективного алгоритму локалізації еволюціонуючих порожнин. Найбільш зручним інструментом для цього є методи гравіметрії [2-4], тому що гравітаційні поля є найбільш поширеними, вивченими і доступними в геофізиці на даний час. Але слід підкреслити, що задача виявлення еволюціонуючих порожнин має цілий ряд істотних особливостей, які дозволяють віднести ііі рішення до окремого підкласу задач обчислювальної геофізики.

Перш за все, потрібно визначити, які саме еволюціонуючі порожнини будуть надалі розглядатися. Однією з головних характеристик еволюціонуючих порожнин $\epsilon$ їх середня швидкість руху та час потенційного виходу на поверхню Землі. Деякі з порожнин мігрують дуже повільно, перебуваючи майже в стаціонарному стані протягом декількох років, принаймі більшу частину часу свого існування. Відстежити їх еволюцію в часі на цьому етапі практично неможливо - заважають похибки вимірювань гравіметра, зміни регіонального фону, постійний видобуток руди в кар'єрі. Кожен 3 цих факторів впливає на процес гравіметричних вимірювань значно більше, ніж вплив майже непомітного руху порожнини. 3 іншого боку, зовсім повільна еволюція таких порожнин робить їх відносно безпечними. Тому такі еволюцінуючі порожнини далі розглядатися не будуть.

Значна частина еволюціонуючих порожнин рухається до поверхні з певною помітною середньою швидкістю протягом декількох тижнів, а то і місяців [1], що дає можливість накопи- 
чити достатню інформацію шляхом систематичних вимірювань гравітаційного поля для визначення їхньої локалізації та основних характеристик, перш за все об'єму та траєкторії руху. Саме для цих еволюціонуючих порожнин будуть побудовані алгоритми їх локалізації. Значному часу еволюції таких порожнин сприяє велика глибина сучасних кар'єрів - порядку $300-500$ м і навіть більше. Крім того, можлива ситуація, коли практично стаціонарні порожнини починають рухатись значно швидше, ніж на попередньому етапі свого існування.

Нарешті, рух дуже невеликої частини еволюціонуючих порожнин відбувається стрімко. Таку порожнину, скоріш за все, не вдасться виявити на підставі епізодичних систематичних вимірів гравітаційного поля. Але якщо технічно вдасться забезпечити часті або навіть безперервні результати гравіметричних вимірів за допомогою системи стаціонарних гравіметричних датчиків, то запропоновані в статі алгоритми для виявлення еволюціонуючих порожнин можуть бути застосовані і до цього останнього класу порожнин, причому практично без змін. Однак слід зауважити, що в цьому випадку вартість системи різко зростає за рахунок великої кількості дорогих стаціонарних гравіметрів або великої кількості вимірювань.

Аналіз останніх досліджень і публікацій

Завдання подібного роду відносяться до теорії зворотних некоректних задач, теорія яких активно розвивається в даний час [2-4]. Як відомо, зворотними задачами зокрема називають задачі відновлення структури об'єктів за непрямими даними. Такі задачі виникають в тих випадках, коли внутрішня будова фізичного об'єкта $є$ недоступною для прямого дослідження, в той час як непряма інформація про структуру об'єкта може бути отримана у вигляді вимірюваних фізичних полів, власних або ж тих, що представляють собою відгук об'єкта на заданий зовнішній вплив.

Як вже було сказано вище, для вирішення такого роду задач доцільно використовувати гравітаційні поля, та проблема криється в відсутності математичних та програмних засобів для розв'язання класу задач, що пропонується для розгляду.

\section{Формулювання мети дослідження}

Метою даної роботи $є$ створення математичної моделі пошуку окремої еволюціонуючої порожнини в ізольованій області на основі загального рівняння гравіметрії та розробка ефективних методів розв'язання задач такого типу.

\section{Виклад основного матеріалу}

Як відомо, рішення будь-якої задачі гравіметрії [2] в найбільш повній постановці призводить до тривимірних інтегральних рівнянь першого роду відносно невідомої щільності просторово розподілених джерел гравітаційного поля. У найбільш загальному випадку потрібно визначити невідомий розподіл щільності у всій тривимірній області $D$. Для цього слід вирішити інтегральне рівняння першого роду:

$$
G \cdot \int_{D}\left(z-z_{J}\right) \cdot \rho(x, y, z) / R^{3} \cdot d V=F_{z}\left(M_{J}\right),
$$

тут - $G$ гравітаційна стала, $\rho(x, y, z)-$ об'ємна щільність середовища, $R-$ відстань між поточною точкою об`єму $D$ та точкою спостереження $M_{J}\left(x_{J}, y_{J}, z_{J}\right), J=1, K$, де $K$ - загальна кількість спостережень, $D$ - досліджувана область, в якій локалізовані можливі джерела гравітаційних аномалій - порожнини. Область спостережень знаходиться на поверхні Землі. Зауважимо, що множина точок спостереження лежить поза областю інтегрування, і тому інтеграл в (1) $є$ власним. Через $F_{z}$ позначена вертикальна проекція сили тяжіння в точці спостереження $M_{J}\left(x_{J}, y_{J}, z_{J}\right)$ від усієї області $D$. Також задане значення абсолютної похибки вимірювань гравітаційного поля та усереднена щільність середовища $\rho_{C}$ в області $D$, яка може містити порожнини. В цій постановці основна задача дослідження - виявити значні області простору під поверхнею Землі, де $\rho(x, y, z)=0$.

Для вирішення рівняння (1) потрібно провести його дискретизацію на $N$ елементарних багатогранників $D_{I}$ - скінчених елементів (CE) з постійною щільністю $\rho_{I}$, що не перетинаються, чи точніше, для будь-яких різних СЕ з номерами $I, J$, де $I \neq J$, тоді $\operatorname{mes}\left(\mathrm{D}_{\mathrm{I}} \cap \mathrm{D}_{\mathrm{J}}\right)=0$. В якості CE найбільш зручно обирати прямі паралелепіпеди, бо в цьому випадку коефіцієнти 
системи алгебраїчних рівнянь (СЛАР) відносно середньої щільності СЕ обчислються найбільш просто. Отже, тепер рівняння (1) можна звести до СЛАР виду:

$$
A \rho=F \text {. }
$$

Слід зауважити, що розмірність $N$ СЛАР (2) для реальних задач досить велика, порядку $N=10^{4}$ чи навіть $10^{5}$ невідомих. Наприклад, припустимо що область $D-$ прямий паралелепіпед, розміром $1000 \times 400 \times 300$ м. Якщо $D$ розбити на $N=N x \times N y \times N z$ елементарних багатогранників, де $N x=100, N y=40, N z=30(N x, N y, N z$ - число поділів області по осі $0 X, 0 Y, 0 Z)$, то отримаємо $N=12 * 10^{3}$, а СЕ буде мати розмір $10 \times 10 \times 10$ м.

Крім того, чисельні експерименти показують, що СЛАР (2) має велике число обумовленості, порядку $10^{5}-10^{7}$. Але основна трудність вирішення проблеми полягає не в цьому. Для формування СЛАР потрібно забезпечити постійні виміри в $N$ різних точках, що практично не можливо з технологічних причин для стаціонарних гравіметричних систем. Навіть якщо зменшити розміри області $D$ в кілька разів та збільшити розмір CE, то все одно, виміри в потрібній кількості точок неможливо забезпечити за допомогою стаціонарних гравіметрів. А сучасні аерогравіметричні системи не забезпечують необхідну точність вимірів. Можна зробити висновок, що вирішити дискретизоване рівняння (2) важко. Разом з тим, для визначення характеристик еволюційних порожнин, при наявності систематичних вимірювань, не потрібно рішення рівняння (1), а значить, і СЛАР (2). Покажемо це.

Перш за все, припустимо, що в області $D$ може бути тільки одна еволюціонуюча порожнина в даний момент спостереження в області $D$. Точніше кажучи, їх може бути як завгодно багато, але при цьому область $D$ можна розбити на підобласті $R$ i $S$, такі, що, $D=R \mathrm{U} S$ та $R \cap S=\varnothing$. Причому, розбиття виконано таким чином, щоб сила тяжіння еволюціонуючих порожнин області $S$ в усіх точках області $R$ була істотно нижче абсолютної похибки використовуваного гравіметра, скажімо, на два порядки, і навпаки. В цих умовах підобласті $R$ i $S$ можна аналізувати абсолютно незалежно. Остання умова практично завжди виконана в силу достатньої рідкості виникнення явища еволюції порожнин і їх різної швидкості руху [1]. Але найбільш ймовірно, що вся досліджувана область має тільки одну еволюціонуючу порожнину чи не має їх взагалі.

Це перше основне припущення пропонованної моделі та методу розрахунку.

Для вирішення завдання проведемо дискретизацію рівняння (1) інакше, ніж раніше. 3разу відмітимо, що дискретизація носить віртуальний характер, iї реально не будемо будувати та використовувати. Вона потрібна тільки для аналізу задачі.

Розіб'ємо область $D$ на $N$ непересічних комірок таким чином, щоб в даний момент еволюціонуюча порожнина перебувала повністю тільки в одній комірці і цілком іiї займала. Осередки можуть бути і неоднорідними по щільності, в тому числі можуть містити і стаціонарні порожнини. Тепер зафіксуємо $N$ постійних точок спостереження на денній поверхні Землі, в яких будуть систематично проводитись вимірювання нормальної складової сили тяжіння.

Для врахування нестаціонарного характеру процесу рівняння (1) слід переписати у вигляді еволюційного:

$$
G \int_{D}\left(z-z_{J}\right) \cdot \rho(x, y, z, T) / R^{3} \cdot d V=F_{z}\left(x_{J}, y_{J}, z_{J}, T\right) .
$$

На перший погляд, завдання тільки істотно ускладнилося. Однак траєкторія еволюціонуючої порожнини займає незначну частину області, що дозволяє істотно спростити рішення (3). Виберемо фіксовані моменти часу $T_{K}-$ моменти часу, коли вимірюється нормальна складова сили тяжіння у заданих точках. Будемо вважати, що щільність середовища в будь-який моменти часу може змінюватись тільки в осередках $D_{I}$ і $D_{I+1}$, які є сусідніми. Тобто порожнина або рухається, або $\epsilon$ непорушною. В інших осередках щільності залишаються незмінними. Іншими словами, ми приймаємо, що порожнина рухається поступово, а обвал в кожен момент часу завжди відбувається тільки в одному новому осередку, або ж порожнина нерухома. Причому порода 3 нового осередку перетікає в старий осередок, обсяг старого осередку дорівнює обсягу нового, щільності породи в осередках також в середньому збігаються Припущення про характер цього процесу підтверджуються фундаментальним дослідженням [1]. Виявляється, в реальності осе- 
редок має певний запас міцності за рахунок механічних властивостей гірських порід, 3 яких складається купол осередка. Цей запас міцності зменшується поступово, під впливом зовнішніх причин, кар'єрних вибухів, перш за все. Саме цим і пояснюється поступовий характер еволюції порожнини, а не іiі повний і миттєвий обвал. Це друге припущення пропонованої моделі і методу розрахунку.

Якщо осередок досить віддалений від денної поверхні Землі, то щільність середовища в осередку можна вважати однорідною і рівною $\rho_{C}$, варіації щільності породи не істотні для розрахунку сили тяжіння. Далі будемо позначати через $F_{J K}$ величину нормальної сили тяжіння в точці спостереження з номером $J$ в момент часу $T_{K}$.

Тепер запишемо загальне рівняння (3) для дискретних моментів часу $T_{K}$ :

$$
G \cdot \int_{D}\left(z-z_{J}\right) \cdot \rho\left(x, y, z, T_{K}\right) / R^{3} \cdot d V=F_{J K}
$$

Виберемо два моменти часу, початковий момент $T_{Q}$ і кінцевий момент $T_{P}\left(T_{Q}<T_{P}\right)$. В момент часу $T_{Q}$ порожнина знаходилась в осередку $D_{Q}$, а в момент часу $T_{P}$ в осередку $D_{P}$. Позначимо:

$$
\begin{aligned}
& I_{P}=G \cdot \int_{D}\left(z-z_{J}\right) \cdot \rho\left(x, y, z, T_{P}\right) / R^{3} \cdot d V=F_{J P} \\
& I_{Q}=G \cdot \int_{D}\left(z-z_{J}\right) \cdot \rho\left(x, y, z, T_{Q}\right) / R^{3} \cdot d V=F_{J Q}
\end{aligned}
$$

Віднімемо рівняння (5) для моменту часу $T_{P} 3$ рівняння (6) для моменту часу $T_{Q}$. В peзультаті отримаємо:

$$
I_{P}-I_{Q}=F_{J P}-F_{J Q}
$$

Проаналізуємо структуру інтегралів (5), (6) та їх різниці (7). Для всіх осередків, крім $D_{P}$ і $D_{Q}$ величина щільності залишилася незмінною згідно з попередніми припущенями. Тому в (7) інтеграли для всіх осередків не ввійдуть, крім $D_{Q}$ i $D_{P}$, положення і величина яких невідомі. У момент часу $T_{Q}$ осередок $D_{P}$ буде вже заповнений, а $D_{Q}$ буде містити порожнину, у момент часу $T_{P}$ все буде навпаки. Тепер припустимо, що в початковий момент часу $T_{Q}$ порожнина перебуває на настільки великій глибині, що величина нормальної сили тяжіння від неї на денній поверхні Землі в усіх точках спостереження істотно нижче абсолютної похибки для використовуваного гравіметра, наприклад, на порядок. Тоді величинами $I_{Q}$ і $F_{J Q}$ в (7) можна знехтувати. Крім того, впливом всього нерухомою середовища також можна знехтувати. В цих умовах (7) зводиться до вирішення спрощеного інтегрального рівняння першого роду:

$$
G \cdot \int_{D_{P}}\left(z-z_{J}\right) \cdot\left(-\rho_{C}\right) / R^{3} \cdot d V=F_{J P} .
$$

У першому наближенні вплив віддаленого однорідного тіла з відомою щільністю можна замінити однорідною кулею, центр якої збігається з центром ваги тіла [2]. Отже, можна уявити рух порожнини у вигляді руху деякого об'єму з негативною щільності, що дорівнює - $\rho_{C}$, в першому наближенні - кулі заданої щільності та невідомого об'єму та положення.

Таким чином, рівняння (8) було зведено до визначення положення центру і радіусу кулі відомої щільності за результатами вимірювань нормальної сили тяжіння на денній поверхні Землі. Права частина рівняння (8) являє собою першу скінчену різницю нормальної сили тяжіння між поточним моментом $T_{P}$ і фіксованим "нульовим" моментом $T_{Q}$, коли вплив порожнини на показання гравіметра був практично нульовим. В силу цього сила тяжіння будь-яких нерухомих областей, як однорідних так і неоднорідних, не впливає на рішення. Наявність стаціонарних порожнин, і навіть порожнин, що еволюціонують, але із значно меншою швидкістю, не впливає на праву частину $(8)$, так як вони входять як в $F_{J Q}$, так і в $F_{J P}$ та взаємно віднімаються.

Однак навіть така спрощена задача (8) при наявності істотних помилок вимірювань нормальної сили тяжіння на денній поверхні Землі $є$ також непростою для чисельного рішення. Головне джерело помилок рішення рівняння (8) - абсолютна похибка гравіметра, що використовується. 
Отже, для визначення параметрів еволюціонуючої порожнини необхідно вирішити наступне завдання. На денній поверхні Землі задані $N$ фіксованих точок спостереження, координати яких відомі. У цих точках систематично, в задані моменти, вимірюється нормальна складова сили тяжіння. Крім того, задані абсолютна похибка вимірювань і середня щільність середовища $\rho_{C}$. Потрібно визначити за результатами спостережень, чи є порожнина еволюціонуючою та іï параметри: об `єм і координати центру ваги на даний момент.

Нормальна складова сили тяжіння в точці спостереження $M_{J}$ від однорідної кулі радіуса $r_{0}$ і щільності $\rho$, центр якої розташований у точці $M_{0}$, визначається [2]:

$$
F_{Z}\left(x_{J}, y_{J}, z_{J}\right)=G \cdot \pi \cdot 4 / 3 \cdot \rho \cdot\left(z_{0}-z_{J}\right) \cdot r_{0}^{3} / R_{J}^{3} .
$$

Тут $R_{J}$ - відстань між точками $M_{0}$ та $M_{J}$. Позначимо:

$$
Q_{J}=3 \cdot F_{Z}\left(x_{J}, y_{J}, z_{J}\right) /(4 \cdot \pi \cdot \rho \cdot G) .
$$

Отже, потрібно вирішити систему нелінійних рівнянь:

$$
\left(z_{0}-z_{J}\right) \cdot r_{0}^{3} / R_{J}^{3}=Q_{J}, J=1, N
$$

вважаючи невідомими координати центру кулі $M_{0}$ і іï радіус $r_{0}$, причому, число точок спостереження $N$, а значить і рівнянь в системі (10) досить велике, як правило, 50-100 і більше. Отже, система (10) $€$ перевизначенною нелінійною системою рівнянь.

На геометрію точок спостереження не накладається ніяких обмежень: вони можуть бути не обов'язково в одній площині, всі точки можуть бути розташовані на одній прямій і тому подібне. До факторів, що ускладнють вирішення системи (10) відноситься та обставина, що відстань між точками спостереження і проекцією центру кулі на денну поверхню Землі, як правило, велика. Це пов'язане з тим, що в умовах кар'єру не завжди можна знайти зручну точку спостереження для виконання вимірювань. Але основна складність вирішення системи (10) в тому, що права частина системи відома зі значною похибкою.

Для вирішення системи (10) був застосований нелінійний метод найменших квадратів. На рис. 1 наведені результати підсумкових чисельних експериментів. Метою цього чисельного експерименту було визначення впливу похибки гравіметра і параметрів системи спостереження на достовірність визначення параметрів еволюціонуючої порожнини. Для розрахунку була обрана куля радіусом 25 м, центр якої мав фіксовану координату $X_{C}=40$, а решта координат були довільними.

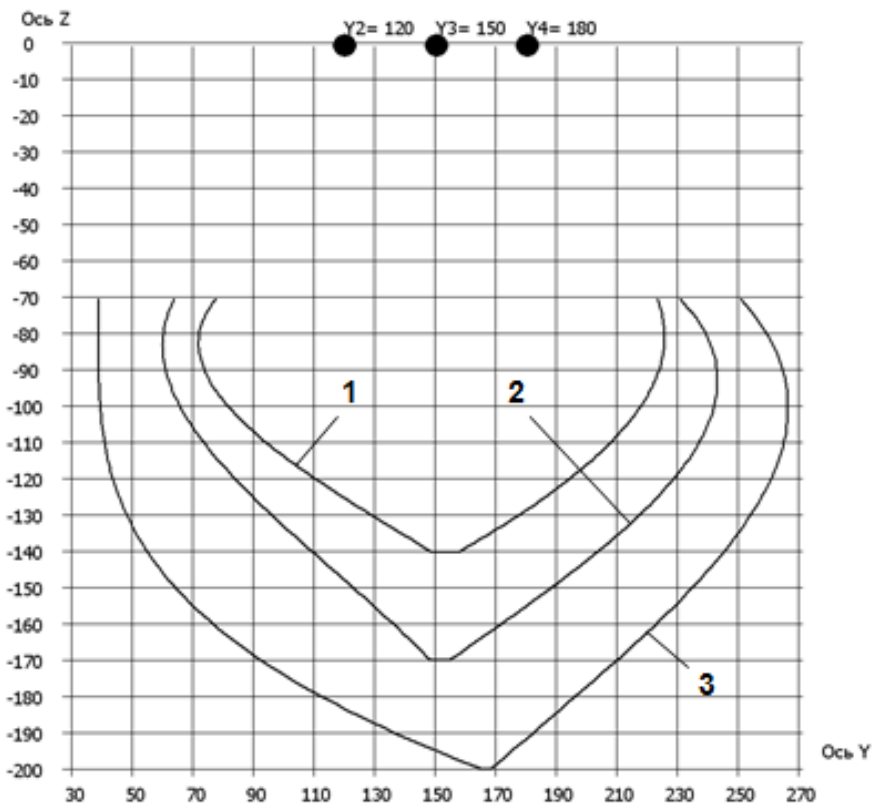

Рuc. 1. Геометрія області достовірного визначення параметрів кулі при абсолютній похибці гравіметра: $1-0.03$ мГал; $2-0.02$ мГал; $3-0.01$ мГал 
Для різних рівнів похибок були розраховані зони точного визначення параметрів кулі. Точки спостереження були розміщені на трьох прямих: перша лінія спостереження має координату $Y=120$, на ній 20 точок, на другій -3 координатою $Y=150-10$ точок, третя $Y=180-20$ точок.

\title{
Висновки
}

1. Запропоновано метод виявлення великого класу еволюціонуючих порожнин на підставі рішення спрощених інтегральних рівнянь першого роду. Отримано розрахункові формули пропонованого методу.

2. Запропоновано ефективний алгоритм розрахунку параметрів еволюціонуючих порожнин при наявності значної абсолютної похибки вимірювань.

3. Проведено чисельні експерименти для вивчення ефективності запропонованих алгоритмів по визначенню еволюційних порожнин при різних рівнях похибки гравіметра i конфігураціях вимірювальної системи.

4. На основі запропонованих алгоритмів реалізований спосіб розрахунку геометрії області, в кожній точці якої можна було б достовірно визначити всі інтегральні параметри порожнини.

\section{Список використаної літератури}

1. Сазонов В.А., Сосик Д.И. Геофизика в маркшейдерском деле. М.: Недра, 1989. 120 с.

2. Гравиразведка. Справочник геофизика / под редакцией Е.А. Мудрецовой. М.: Недра, 1990. $608 \mathrm{c}$.

3. Тихонов А.Н., Арсенин В.Я. Методы решения некорректных задач. М.: Наука, 1979. 288 с.

4. Верлань А.Ф., Сизиков В.С. Интегральные уравнения: методы, алгоритмы, программы. Київ: Наукова думка, 1986. 544 с.

\section{MATHEMATICAL SIMULATION OF THE SEARCH FOR EVOLUTIONARY LOCAL CAVITIES \\ Smolyansky P., Kozikov A., Shamray O.}

\begin{abstract}
The search for voids of man-made and natural nature is becoming an increasingly important task in modern conditions. The main danger is evolving voids, ie voids that change their position in space over time. The task of localization of such cavities at extraction of minerals in the open way, in boards - lateral walls of quarries becomes especially actual. At the same time, constant technological explosions provoke the formation and migration of voids. Elimination of the consequences of landslides requires significant funds, and most importantly, possible human casualties.

As is known, the solution of any problem of gravimetry in the most complete formulation leads to three-dimensional integral equations of the first kind with respect to the unknown density of spatially distributed sources of the gravitational field. In the most general case, it is necessary to determine the unknown density distribution in the entire three-dimensional region $\mathrm{D}$. To do this, we must solve the integral equation of the first kind. In this statement, the main task of the study is to identify significant areas of space below the Earth's surface, where the density of the rock is zero.

To solve the equation of gravimetry it is necessary to discretize it on elementary polyhedra finite elements (CE) with constant density

It should be noted that the dimensionality for real problems is quite large. In addition, numerous experiments show that the conditionality of SLAR is large. But this is not the main difficulty in solving the problem. For the formation of SLAR it is necessary to provide systematic measurements at
\end{abstract}


different points, the number of which coincides with the number of CE, which is almost impossible for technological reasons. The article proposes methods to solve this problem.

A method for detecting a large class of evolving cavities based on the solution of simplified integral equations of the first kind is proposed. The calculation formulas of the proposed method are obtained. An effective algorithm for calculating the parameters of evolutionary cavities in the presence of a significant absolute measurement error has been developed. Numerical experiments were also performed to study the efficiency of these algorithms for determining the parameters of evolutionary cavities at different levels of gravimeter error and configurations of the measuring system.

\section{References}

[1] Sazonov V.A, Sosik D.I. (1989) Geofizika v markshrederskom dele. [Geophysics in surveying]. Moscow: Nedra [in Russian].

[2] Gravirazvedka. Spravochnik gejfizika (1990) [Engraving exploration/ Handbook of geophysics] / Edited by Mudretsova E.A. Moscow: Nedra [in Russian].

[3] Tikhonov A.N., Arsenin V.Y. (1979) Metodi reshenia nekorrektnix zadach. [Methods for solving incorrect problems]. Moscow: Nauka [in Russian].

[4] Verlan A., Sizikov V. (1986) Integralnie uravnenia: metodi,algoritmi, programmi. [Integral equations: methods, algorithms, programs]. Kiev: Naukova dumka [in Ukraine]. 